\title{
2020: A TECNOLOGIA DIGITAL JÁ É UMA REALIDADE NAS ESCOLAS RURAIS?
}

NAIRANA HOFFMANN SEDREZ UNIVERSIDADE FEDERAL DE PELOTAS PELOTAS, RIO GRANDE DO SUL, BRASIL NAIRANA_SEDREZ@HOTMAIL.COM

RAFAEL VETROMILLE CASTRO UNIVERSIDADE FEDERAL DE PELOTAS PELOTAS, RIO GRANDE DO SUL, BRASIL RAFAEL.VETROMILLE@UFPEL.EDU.BR 


\section{0: A TECNOLOGIA DIGITAL JÁ É UMA REALIDADE NAS ESCO- LAS RURAIS?}

Resumo: Este trabalho é um estudo de casos múltiplos feito em duas escolas públicas da zona rural de Pelotas-RS, buscando verificar o quão presentes as Tecnologias Digitais da Informação e Comunicação (TDIC) estão nas aulas no ano de 2020. Pelos dados obtidos em um questionário online, verificou-se que todos os professores reconhecem a importância das TDIC na educação, mas sua frequência de uso ainda é muito baixa.

Palavras-chave: Tecnologias Digitais da Informação e Comunicação; Educação; Zona rural.

\section{0: ¿LA TECNOLOGÍA DIGITAL YA ES UNA REALIDAD EN LAS ESCUELAS RURALES?}

Resumen: Se realizó un estudio de caso múltiple en dos escuelas públicas de la zona rural de Pelotas-RS. El objetivo fue verificar lo presentes que están las Tecnologías de la Información y la Comunicación Digitales (TICD) en las clases en el año 2020. Las respuestas a un cuestionario en línea señalan que, aunque los docentes reconocen la importancia de las TICD, su frecuencia de uso sigue siendo muy baja.

Palabras clave: Tecnologías de la Información y la Comunicación Digitales; Educación; Zona rural.

\section{0: IS DIGITAL TECHNOLOGY ALREADY A REALITY IN RURAL SCHOOLS?}

Abstract: This work is a multiple case study carried out in two public schools in the countryside of Pelotas-RS, seeking to verify how present the Digital Information and Communication Technologies (DICT) are in classes in the year of 2020. From the data obtained in an online questionnaire, it was found that all teachers recognize the importance of DICT in education, but their frequency of use is still very low.

Keywords: Digital Information and Communication Technologies; Education; Countryside.

\section{E AS TECNOLOGIAS DIGITAIS CHEGARAM ÀS ESCOLAS}

Provavelmente, a tecnologia mais antiga que conhecemos seja a linguagem. Apesar de sermos constituídos por um aparelho fonador que nos habilita a falar e, portanto, essa ser uma capacidade inata nossa, a linguagem foi um recurso desenvolvido pela mente humana com engenhosidade para que através dela pudéssemos desempenhar inúmeras ações e atingir uma 
infinidade de objetivos. Da sua forma oral, passando pela escrita e chegando à forma digital, a linguagem acompanhou o processo evolutivo das tecnologias e, ao mesmo tempo que foi a protagonista no desenvolvimento de novos aparatos tecnológicos, foi, ela mesma, transformada e aprimorada como resultado dessa evolução, relação similar àquela feita por Leffa em 2009: "A tecnologia alimenta a língua e a língua alimenta a tecnologia, num verdadeiro processo de retroalimentação." (n.p.).

Fica claro, assim, que temos utilizado tecnologias para os mais diversos fins desde o início da humanidade e cada tecnologia que tivemos, ou que ainda temos, em algum momento da história foi considerada uma inovação. Steven Johnson afirma que as inovações "[...] geralmente surgem como uma tentativa de resolver um problema específico, mas, uma vez que entram em circulação, acabam provocando outras mudanças que teriam sido difíceis de prever" (2015, p. 9). Segundo o mesmo autor, a inovação, por vezes, evidencia uma deficiência que já estava ali, mas que ainda não havíamos percebido. Esse pode ser o caso da relação entre as Tecnologias Digitais da Informação e Comunicação (TDIC) e a educação.

No Brasil, há - pelo menos - duas décadas os computadores já passaram a fazer parte do arsenal de ferramentas de ensino que compõem as escolas. Sabemos que essa realidade ainda não se aplica a todas as escolas brasileiras, haja vista que muitas escolas se encontram em zonas de difícil acesso, ou, por questões que não cabem ser abordadas aqui, têm uma infraestrutura muito precária e investimentos financeiros quase inexistentes.

As tecnologias, de modo geral, têm uma importância colossal na vida e no desenvolvimento dos sujeitos, pois, com base nas ideias de Clark, o cérebro por si só não é tão impressionante; são as ferramentas à nossa volta que nos tornam tão espertos (CLARK, 2003 apud LEVY, 2003, p. 14). Assim, tendo em mente o triângulo de mediação de Vygotsky, as TDIC desempenham o papel de instrumento mediador (artefato) entre o aluno (sujeito) e o conhecimento a ser construído (objeto). Vygotsky evidencia que no processo de mediação diversas funções relacionadas ao uso da ferramenta são ativadas, ao mesmo tempo que outros processos são dispensados. Além disso, vários aspectos dos processos mentais relacionados ao ato instrumental são também modificados, já que são "Direcionados para a solução de um problema apresentado pelo objeto, [enquanto] a ferramenta determina sua coordenação e curso." (1997, p. 87 - tradução nossa). O grande problema é que sem o uso de ferramentas adequadas na educação o potencial do cérebro 
humano é subaproveitado, como discute Hilário Bohn:

Segundo Smith (1996) a escola moderna não oferece condições para o cérebro exercer as suas funções. O cérebro naturalmente estrutura, relembra, imagina, intui, mas a escola por causa de seu processo inibidor impede que cumpra as suas funções. O ensino inovador tenta resgatar as condições necessárias para este cérebro cumprir suas funções. (BOHN, 2001, p. 120).

Portanto, devemos, enquanto professores, utilizar as TDIC para melhorarmos nossas práticas pedagógicas e o processo de ensino e aprendizagem, potencializando as funções cognitivas dos estudantes e fortalecendo a sua autonomia, "[...] oferecendo-lhes condições e ferramentas para acessar e interagir criticamente com diferentes conhecimentos e fontes de informação" (BRASIL, 2018, p. 60). Entretanto, retomando a reflexão de Steven Johnson sobre a deficiência que vem à tona com uma inovação, cabe fazermo-nos alguns questionamentos: estamos fazendo uso adequado das TDIC para além da sua dimensão técnica ou estamos apenas transferindo as atividades do livro e da lousa para a tela? Até que ponto a invasão tecnológica não veio para mostrar que a falha na formação dos alunos já acontecia há muito tempo com os métodos tradicionais de ensino? E até que ponto essas falhas não continuam presentes no processo de ensino na era digital? E, finalizando com uma questão que antecede todas as outras: duas décadas após o boom tecnológico, estamos finalmente utilizando as TDIC em nosso sistema de ensino?

Com base nessas inquietações, para este trabalho fizemos um estudo de casos múltiplos incorporados (YIN, 2001) de duas escolas públicas de ensino fundamental da zona rural de Pelotas-RS com o objetivo de verificar se os professores dessas escolas utilizam as TDIC em suas aulas, com que frequência as utilizam e qual a sua visão sobre o uso de tecnologias digitais em sala de aula. Para entender a importância e o impacto do uso das TDIC na educação, a Teoria da Complexidade (LARSEN-FREEMAN, 1997; MORIN, 1995; PAIVA, 2005) atuará como pano de fundo desta pesquisa, para a qual teremos como base a Teoria da Atividade (ENGESTRÖM, 1999; VYGOTSKY, 1997; VYGOTSKY; LURIA; LEONTIEV, 2010), por entendermos que "A aprendizagem não se dá num vácuo ou apenas com o uso dos recursos internos do indivíduo. É necessário o apoio de recursos externos para que o indivíduo se modifique internamente e aprenda." (LEFFA, 2009, n.p). 


\section{AS VISÕES ESTIGMATIZADAS SOBRE AS TECNOLOGIAS DIGITAIS E AS ESCOLAS RURAIS}

Em 2001, em sua dissertação de mestrado sobre $O$ uso das novas tecnologias em sala de aula, Diniz anunciava:

Uma nova era na Educação! Um mundo novo se abre em acelerado processo de globalização; é uma sociedade espantosamente dinâmica, instável e evolutiva, onde o elemento fundamental e decisivo é a mudança de paradigmas. A informação associada à robótica e a outras inovações tecnológicas de fundo, estão definitivamente encerrando a era industrial e inaugurando em novo tempo, a era pós-industrial, uma era sem precedentes. (2001, p. 1)

Praticamente duas décadas mais tarde, o site do jornal Tribuna do Norte publicava a matéria Especialistas alertam sobre uso de celular na escola: vilão ou aliado?, na qual o cenário da relação "escola e celular" era apresentado:

Levar ou não levar o celular para a escola? Esta é uma dúvida de muitos pais que já disponibilizam o aparelho eletrônico para os fiIhos desde a infância. De fato, os smartphones são uma ferramenta indispensável para a comunicação, mas os especialistas alertam: seu uso na sala de aula - como em casa também - deve ser controlado e orientado por adultos, para que haja maior aproveitamento de seus benefícios. E o desafio das escolas é utilizar o celular como aliado da aprendizagem. (TRIBUNA DO NORTE, 2020, n.p)

Eis que o mundo novo que se abriu há cerca de 20 anos ainda está sendo explorado e, como é natural frente a qualquer inovação, ainda enfrenta a persistente resistência de professores e equipes diretivas das escolas no Brasil. As dúvidas são de todos os envolvidos no processo educacional: docentes, diretores, coordenadores, familiares e alunos. Enquanto a sociedade ainda tenta encontrar o ponto de equilíbrio para o uso das TDIC, o retrato da sala de aula, especialmente da rede pública, não mudou muito daquele conhecido pelos nossos avós. Com base nos pensamentos de Paiva, podemos entender um pouco melhor a morosidade nesse processo de adaptação às TDIC:

Transformações acontecem através da amplificação de pequenas diferenças no comportamento de um sistema, quando novidade, criatividade e inovação podem emergir. No entanto, no caso do contexto educacional, não basta haver um novo artefato disponí- 
vel para alunos e professores, pois muitos outros elementos interagem no sistema complexo da Educação interferindo na difusão da inovação. (PAIVA, 2012, p. 16)

Há, por trás da chegada das tecnologias digitais no contexto escolar, toda uma prática sócio-histórico-cultural estabelecida que precisa abrir espaço para a inovação; professores que, apegados às suas únicas memórias de o que é uma sala de aula, resistem à sua reinvenção ao ter que ser um professor que eles nunca conheceram. É evidente que o professor, refém de todo um sistema educacional e político, encontra dificuldades ao tentar dar um passo adiante em direção às inovações escolares. Ainda citando Paiva, "[a] apropriação das inovações gera tensões, resistências e censura e as mudanças não estão diretamente associadas aos artefatos, mas sim a atratores como crenças e conceitos cristalizados na comunidade." (2012, p. 16). Dessa forma, é compreensível que o professor, mesmo sendo já usuário das TDIC fora do contexto escolar, seja levado a enxergar o smartphone do aluno como um vilão, pois este artefato não pertence ao conceito que ele tem de sala de aula. O que é necessário, então, para que as TDIC passem a ser aliadas dos professores?

\begin{abstract}
A inovação exige por parte do professor e dos alunos uma atitude de contínua aprendência. O novo só pode florescer se a mente estiver isenta de crenças, ideologias, dogmas restritivos. $O$ sistema de crenças faz o filtro de nossa aprendizagem e de nosso ensino. O novo somente pode participar de nossa estrutura mental à medida que admitimos que a estrutura atual pode e deve ser alterada. Isto certamente não está de acordo com a nossa cultura patriarcal que trabalha com o definitivo, com o coerente e o racional. (BOHN, 2001, p. 120)
\end{abstract}

Se essa aceitação de inovações é difícil para a comunidade escolar da zona urbana, onde as mudanças chegam mais rapidamente, para os moradores do campo ela tende a ser ainda mais árdua. Os processos de mudanças são diferentes nesses locais não porque os sujeitos são mais ou menos capazes, mas sim, como aponta Arroyo, em decorrência de as políticas educativas públicas, via de regra, serem pensadas para os cidadãos do espaço urbano, lugar idealizado de excelência, e não para aqueles da zona rural, lugar de atraso e tradicionalismo cultural (ARROYO, 2007). 
esquecidos. A palavra adaptação, utilizada repetidas vezes nas políticas e nos ordenamentos legais, reflete que o campo é lembrado como o outro lugar, que são lembrados os povos do campo como os outros cidadãos, e que é lembrada a escola e os seus educadores(as) como a outra e os outros. A recomendação mais destacada é: não esquecer os outros, adaptando às condições do campo a educação escolar, os currículos e a formação dos profissionais pensados no paradigma urbano. (ARROYO, 2007, p. 158-159 - grifos do autor).

Como consequência desse desprestígio pelos moradores e escolas do campo, acontece o sucateamento desses espaços, deixando a adaptação das políticas e a preocupação com o outro no papel, enquanto se investe nas escolas urbanas para que os números sejam bons onde há mais chances de o serem. No entanto, para espanto de entidades políticas e da sociedade como um todo, a notícia veiculada pelo UOL em 2018 era a de que Escola da zona rural de Alagoas supera pobreza e tem maior Ideb do país. No corpo do texto, os detalhes surpreendiam ainda mais aqueles que tentavam entender o que estavam lendo:

Com estrutura modesta e alunos que ainda enfrentam a fome no dia a dia, a escola rural conseguiu um feito inédito na educação do país: teve média 9,9 no Ideb (Índice de Desenvolvimento da Educação Básica). A avaliação foi a melhor entre todas as escolas de ensino fundamental inicial avaliadas pelo indicador. Para se ter ideia, a média do Brasil foi de 5,8 em 2017. (MADEIRO, 2018, n.p. grifos do autor)

Notícias como essa evidenciam o que foi discutido até aqui: se, por um lado, o sujeito do campo é sempre o outro e, consequentemente, a maioria das escolas rurais não recebe investimentos adequados, por outro, os sujeitos do campo não são menos capazes do que os sujeitos da zona urbana. Se, sem grandes investimentos financeiros, as escolas rurais já alcançam 9, 9 no Ideb, imaginemos o boom educacional que aconteceria caso elas recebessem dispositivos tecnológicos eficientes, velocidade apropriada de conexão com a internet e formação significativa em TDIC ofertada aos professores.

\section{O PROCESSO DE INVESTIGAÇÃO SOBRE TECNOLOGIAS DIGITAIS NAS ESCOLAS RURAIS}


A base desta pesquisa é a metodologia de estudo de casos múltiplos incorporados (YIN, 2001), pois analisou-se duas escolas de zona rural (dois estudos de caso) e considerou-se os professores como subunidade de análise, em oposição a uma análise global das escolas, que resultaria em um projeto holístico (YIN, 2001).

As duas escolas rurais selecionadas, ambas locais de trabalho da autora desta pesquisa, pertencem ao município de Pelotas e serão denominadas de Escola A e Escola B. A Escola A fica a cerca de $40 \mathrm{~km}$ do centro de Pelotas e possui 230 alunos divididos entre Pré e $9^{\circ}$ ano. A Escola B fica a aproximadamente $17 \mathrm{~km}$ de Pelotas e conta com um total de 320 alunos, os quais estão matriculados na Educação Infantil, no Ensino Fundamental ou na Educação para Jovens e Adultos.

Para a investigação quanto ao uso de TDIC nas escolas rurais, foi elaborado um questionário online utilizando o Google Forms, o qual foi respondido por professores das duas escolas de forma anônima. O questionário contou com 19 perguntas, das quais 15 eram objetivas e 04 discursivas. As perguntas abordavam idade, tempo de trabalho, área em que residiu a maior parte da vida (urbana/rural/outra), escola em que trabalha, frequência de trabalho na escola, turmas para as quais dá aula, disciplina(s) trabalhada(s) e questões referentes à experiência e opinião do professor quanto ao uso de tecnologias digitais em sala de aula.

\section{UMA ANÁLISE SOBRE AS TDIC NAS ESCOLAS RURAIS}

Na coleta de dados realizada por meio de questionário online, obtivemos um total de 20 professores participando da pesquisa. Apresentaremos, agora, uma análise das respostas dos participantes da pesquisa, as quais foram organizadas em 6 categorias de dados: (1) Perfil; (2) Perfil profissional; (3) Percepção da importância das TDIC na educação; (4) Percepção do uso das TDIC em suas aulas; (5) Formação em TDIC voltadas à educação; (6) Percepção de domínio de ferramentas digitais.

Do total de professores que responderam ao questionário, 9 trabalham na Escola A e 11 trabalham na Escola B. Para exibirmos os dados de forma mais fidedigna e organizada, apresentaremos a análise da Escola A e da Escola B separadamente, já seguindo o que sugere Yin (2001) para esse tipo de estudo de caso.

\section{1 $1^{\circ}$ Caso: Escola A}


Na categoria "Perfil" dos professores da Escola A, todos os participantes da pesquisa tinham entre 31 e 55 anos. Na categoria "Perfil profissional", 2 participantes já trabalham como professores há, no máximo, 5 anos, outros 3 há 11-15 anos, e os demais há 21-35 anos. Professores de diferentes disciplinas, desde o Pré-1 até o $9^{\circ}$ ano, incluindo o professor de Sala de Recursos, responderam ao questionário.

Na categoria "Percepção da importância das TDIC na educação", a maioria dos professores, com base em uma escala de 1 a 5 , atribui um grau elevado de importância ao tema em questão: grau 3 (33\%), grau 4 (44\%) e grau 5 (22\%). Ao serem questionados sobre o grau de importância das tecnologias digitais nas suas disciplinas, a maioria dos professores manteve o mesmo valor atribuído à questão anterior, mas dois professores apresentaram um posicionamento diferente: o de Ensino Religioso, que havia indicado o grau 3 na pergunta anterior, indicou grau 4 de importância das tecnologias digitais para a sua disciplina, ao passo que o professor de Educação Física, que havia indicado grau 5 na pergunta anterior, indicou grau 4 nessa, o que é bastante coerente se atentarmos para a área de ensino dele. Apresentamos a seguir algumas respostas que indicam o que os sujeitos da pesquisa pensam sobre o assunto, e realçamos trechos que nos parecem merecer destaque.

\section{Quadro 1 - Percepções de professores da Escola A}

\begin{tabular}{|l|l|}
\hline \multicolumn{1}{|c|}{ Identificação } & \multicolumn{1}{c|}{ Percepção } \\
\hline $\begin{array}{l}\text { Professor dos anos finais - Ensino } \\
\text { Religioso (P1) }\end{array}$ & $\begin{array}{l}\text { "Nos dias atuais a tecnologia faz parte da vida do ser } \\
\text { humano, a escola precisa acompanhar a evolução, não tem } \\
\text { como termos bons resultados se pararmos no tempo." }\end{array}$ \\
\hline $\begin{array}{l}\text { Professor dos anos iniciais }-3^{\circ} \text { ano } \\
(\mathrm{P} 2)\end{array}$ & $\begin{array}{l}\text { "O uso da tecnologia digital poderia enriquecer a aula, } \\
\text { mostrando imagens, videos, atividades on-line, pesquisa } \\
\text { trazer para "perto" aquilo que para muitos alunos talvez } \\
\text { nem exista." }\end{array}$ \\
\hline $\begin{array}{l}\text { Professor dos anos iniciais e finais } \\
\text { - Espanhol (P3) }\end{array}$ & $\begin{array}{l}\text { "É um recurso que auxilia na aula, porém não é algo } \\
\text { extremamente necessário, inclusive dificilmente se tem } \\
\text { tempo suficiente para usar." }\end{array}$ \\
\hline $\begin{array}{l}\text { Professor dos anos iniciais e e } \\
\text { projeto-Música (P4) }\end{array}$ & $\begin{array}{l}\text { "Considero que não é o mais importante, mas é uma } \\
\text { ferramenta muito útil em muitas situaçóes, que os alunos } \\
\text { dominam, e pode ser usado a nosso favor." }\end{array}$ \\
\hline
\end{tabular}

Fonte: autores.

As considerações feitas por P1 e P2 evidenciam uma visão bastante positiva dos professores quanto aos benefícios e à necessidade de se usar TDIC. Por outro lado, $\mathrm{P}_{3}$ e P4, apesar de reconhecerem a importância das tecnologias digitais, defendem que isso não é algo essencial na sala de aula, e P3 
chega a expor o problema da falta de tempo para o uso das TDIC em aula.

Na categoria "Formação em TDIC voltadas à educação", destacamos que $67 \%$ dos docentes nunca participaram de formação nessa área. A justificativa dada por esses professores foi a mesma: falta de oportunidade (uma das três justificativas sugeridas na pergunta). Fazendo o cruzamento dos dados obtidos, apuramos que há professores que dão aula há 20 ou 30 anos e ainda não puderam comparecer a uma formação em TDIC voltadas para a educação.

Na categoria "Percepção do uso das TDIC em suas aulas", todos os 9 professores afirmaram já ter utilizado notebook ou computador alguma vez; 7 já utilizaram smartphones em sala de aula; apenas 3 fizeram uso do tablet em aula; e 4 professores já utilizaram o Computador Interativo (distribuído pelo governo). Em resumo, 3 professores já haviam utilizado todas as tecnologias digitais mencionadas e só 1 professor havia feito uso exclusivamente de computador/notebook em suas aulas até o momento da pesquisa (todos os outros indicaram já ter utilizado pelo menos duas das TDIC apresentadas).

Apesar de observarmos que os professores não só acham importante utilizar TDIC em aula, como também já colocaram algumas tecnologias digitais a serviço de suas práticas pedagógicas, também ficou evidente que essa prática ainda não foi incorporada de forma rotineira nas suas aulas. Prova disso é a frequência com que os professores afirmaram usar cada tecnologia digital em aula, conforme disposto na Tabela 1 (já organizada em ordem decrescente de uso de tecnologias digitais - da mais à menos usada).

Tabela 1 - Frequência de uso de tecnologias digitais em aula na Escola A

\begin{tabular}{|c|c|c|c|c|c|c|c|}
\hline \multirow{2}{*}{$\begin{array}{c}\text { Tecnologia } \\
\text { digital }\end{array}$} & \multicolumn{7}{|c|}{ Frequência de uso em aula } \\
\hline & Nunca & $\begin{array}{c}\text { 1x por } \\
\text { trimestre }\end{array}$ & $1 \mathrm{x}$ por mês & $\begin{array}{c}1 \mathrm{x} \text { a cada } \\
15 \text { dias }\end{array}$ & $\begin{array}{l}1 \mathrm{x} \text { por } \\
\text { semana }\end{array}$ & $\begin{array}{l}3 \mathrm{x} \text { por } \\
\text { semana }\end{array}$ & $\begin{array}{c}\text { Todas as } \\
\text { aulas }\end{array}$ \\
\hline $\begin{array}{l}\text { Computador/ } \\
\text { Notebook }\end{array}$ & 0 & 4 & 2 & 2 & 1 & 0 & 0 \\
\hline Smartphone & 2 & 2 & 2 & 1 & 0 & 0 & 2 \\
\hline $\begin{array}{l}\text { Computador } \\
\text { interativo } \\
\text { (distribuido pelo } \\
\text { governo) }\end{array}$ & 5 & 3 & 0 & 0 & 0 & 1 & 0 \\
\hline Tablet & 6 & 2 & 0 & 0 & 1 & 0 & 0 \\
\hline
\end{tabular}

Fonte: autores.

Como pode ser percebido, a maior parte das respostas obtidas concentra-se nas três primeiras colunas da tabela, indicando que são minoria os 
professores que utilizam alguma TDIC em suas aulas com frequência igual ou superior a duas vezes por mês. No entanto, apesar de a maioria dos docentes não ter o hábito de incorporar as tecnologias digitais às suas aulas, 6 dos 9 professores disseram já ter elaborado uma atividade digital, o que nos dá indícios de que os professores não fazem uso das TDIC "apenas" reutilizando materiais tais quais os encontram, mas também transportam sua autoria de materiais de fora para dentro do mundo digital.

Ao serem questionados sobre o que lhes ajudaria a utilizar as tecnologias digitais com maior frequência em suas aulas, 2 professores indicaram a importância de mais acesso à internet para os alunos e em todos os espaços da escola, 4 expressaram a necessidade de cursos nessa área, 1 apontou que falta domínio de aplicativos, e 3 falaram sobre a falta de tempo - 2 se referindo ao tempo em sala de aula e 1 ao tempo de planejamento. Apesar de vários professores terem manifestado a necessidade de obter formação em TDIC, no Gráfico 1 podemos observar que eles já lançaram mão de várias ferramentas tecnológicas para enriquecer sua prática pedagógica.

Gráfico 1 - Ferramentas tecnológicas utilizadas em aula na Escola A

- Dicionário on-line

Editor de texto (ex: "Word")

- E-mail

- Facebook

- Google Maps

Google (pesquisa)

instagram

- Jogos educativos on-line

- Khan Academy

Powerpoint

- Skype

- Tradutor

- WhatsApp

n Wikipédia

Youtube

- Outros: Afinador Cifraclub

a Outros: Cifraclub

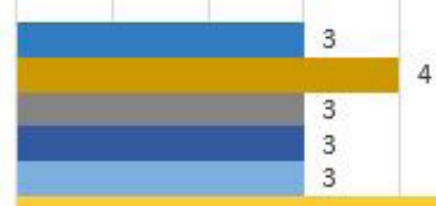

4

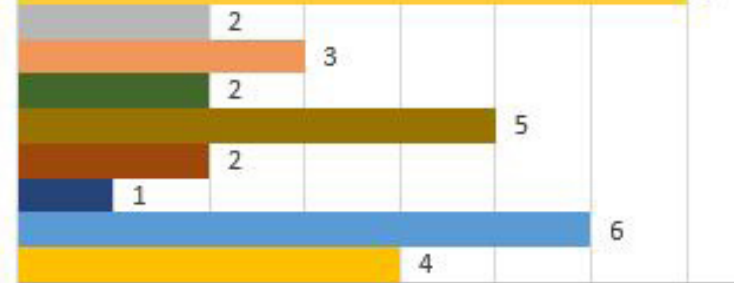

4

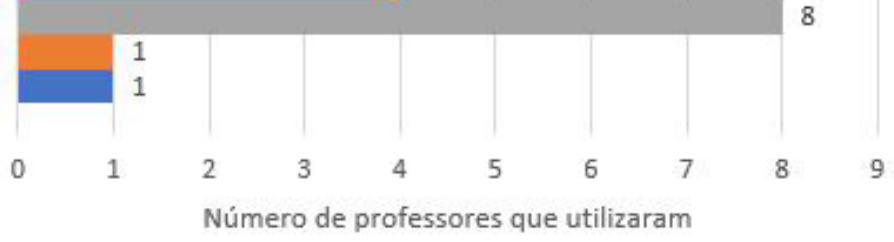

Fonte: autores.

Percebemos, a partir das respostas obtidas, que as três ferramentas tecnológicas utilizadas por mais professores foram, respectivamente, as de gravação/exibição de vídeos, pesquisa e comunicação - e aqui cabe sublinhar que são todas de uso online. O segundo grupo de ferramentas mais 
adotadas pelos professores contém aquelas relativas à apresentação de conteúdo, edição de texto e leitura e obtenção de informações - ferramentas que apesar de serem simples e populares, provavelmente não sejam tão utilizadas por funcionarem como substitutos de atividades que podem ser feitas em sala de aula sem suporte digital. Dentre as ferramentas menos utilizadas estão aquelas que, ou podem ser vistas pelos professores como sendo ineficazes para fins pedagógicos (redes sociais, jogos), ou podem apresentar barreiras tecnológicas para seu uso (e-mail, Skype - por dependerem de cadastros dos alunos), ou, finalmente, são de uso mais específico (tradutor, Afinador Cifraclub etc.) de forma que disciplinas mais pontuais acabem por utilizá-las. É importante informar que, por não terem sido utilizadas por nenhum professor, as seguintes ferramentas tecnológicas foram suprimidas do Gráfico 1: ELO - Ensino de Línguas Online, Google Classroom, Kahoot, Nearpod, Prezi e Twitter.

A última categoria de análise, "Percepção de domínio de ferramentas digitais", nos mostra que, na média, os professores consideram que tenham um domínio regular do computador/notebook e do smartphone, e pouco domínio do tablet e do computador interativo. Vale detalhar que o valor de ótimo domínio só foi indicado uma vez e por apenas um professor, quando se referia ao uso de computador/notebook, ao passo que o valor de nenhum domínio foi assinalado dez vezes, sendo metade delas relacionada ao uso de computador interativo e uma relacionada ao uso de computador/notebook. Fazendo um cruzamento de dados, observamos que há uma tendência de proporção entre domínio da tecnologia digital e frequência de uso, de forma que quanto maior foi o domínio indicado pelo professor acerca de cada TDIC, maior foi a sua frequência de uso em sala de aula - sendo o inverso também verdadeiro.

\section{2 $2^{\circ}$ Caso: Escola B}

Na categoria "Perfil" dos professores da Escola B, percebemos que dos 11 professores participantes da pesquisa, um tem entre 26-30 anos, outros três entre 31-40 e a maioria tem entre 51-60 anos. Quanto ao "Perfil profissional”, a maioria trabalha há mais de 21 anos nessa área, e dividem-se nos anos escolares do $1^{\circ}$ ao $9^{\circ}$ ano do Ensino Fundamental, EJA (anos iniciais e finais), Substituição e Estudos de Recuperação - não tendo a participação de professores da Educação Infantil e da Sala de Recursos.

Na categoria "Percepção da importância das TDIC na educação", todos os professores reconhecem a importância do uso de tecnologias digitais na 
educação. Apresentamos no Quadro 2 algumas considerações que os professores teceram sobre o assunto.

Quadro 2 - Percepções de professores da Escola B

\begin{tabular}{|l|l|}
\hline \multicolumn{1}{|c|}{ Identificação } & \multicolumn{1}{c|}{ Consideração } \\
\hline $\begin{array}{l}\text { Professor dos anos finais do EJA - }- \\
\text { Geografia (P5) }\end{array}$ & $\begin{array}{l}\text { "São recursos que enriquecem, porém, as aulas podem ser } \\
\text { desenvolvidas com qualidade sem eles." }\end{array}$ \\
\hline $\begin{array}{l}\text { Professor de substituição - todos } \\
\text { os anos escolares (P6) }\end{array}$ & $\begin{array}{l}\text { A importância não acompanha a estrutura. Formação } \\
\text { para uso das tecnologias ainda está defasada." }\end{array}$ \\
\hline $\begin{array}{l}\text { Professor do } 6^{\circ}, 7^{\circ}, 8^{\circ} \text { e } 9^{\circ} \text { ano - }- \\
\text { Ciências (P7) }\end{array}$ & $\begin{array}{l}\text { "Eu acho de média importância porque acredito que os } \\
\text { alunos do ensino fundamental devem praticar a escrita com }\end{array}$ \\
& $\begin{array}{l}\text { especificas. Mas atualmente as tecnologias digitais são } \\
\text { muito usadas em diversas atividades, então usá-las às } \\
\text { vezes pode ajudar na inclusão destes alunos na próxima } \\
\text { etapa de ensino: o ensino médio." }\end{array}$ \\
\hline $\begin{array}{l}\text { Professor dos anos iniciais e finais } \\
\text { - Espanhol (P8) }\end{array}$ & $\begin{array}{l}\text { "Para mim é bastante importante, pois podemos trazer } \\
\text { para os grupos diferentes tipos de realidades, acentos } \\
\text { linguisticos [sotaques] e atividades que promovam maior } \\
\text { participação do aluno como protagonista." }\end{array}$ \\
\hline $\begin{array}{l}\text { Professor dos anos finais do EJA - }- \\
\text { Inglês (P9) }\end{array}$ & $\begin{array}{l}\text { "Tendo apenas uma aula por semana e dentro do contexto } \\
\text { da EJA, onde os alunos têm bastante dificuldade de } \\
\text { maneira geral, o uso das tecnologias vem como ferramenta } \\
\text { facilitadora e multiplicadora do tempo que os alunos } \\
\text { passam em contato com o idioma." }\end{array}$ \\
\hline
\end{tabular}

Fonte: autores.

Em comparação com a Escola A, os professores da Escola B forneceram considerações mais aprofundadas sobre o assunto, trazendo aspectos enriquecedores para a nossa discussão. Além do $\mathrm{P}_{5}$, outros dois professores entendem a importância das tecnologias digitais, mas as consideram como um recurso não essencial para o desenvolvimento de uma aula com qualidade. Através de P6, percebemos que tanto o aparato tecnológico das escolas quanto a falta de formação dos professores, ainda em 2020, pode ser um empecilho para a consolidação de uma educação mediada pela tecnologia. A consideração feita por P7 parece indicar que há uma leve tendência de os professores acharem importante o uso das TDIC na educação ao mesmo tempo que retiram de si próprios a "responsabilidade" de levar as tecnologias digitais para as suas aulas, ou seja, da mesma forma como $45 \%$ dos docentes nessa escola atribuiu um menor grau de importância às TDIC para as suas aulas do que para a educação em geral, o P7 parece enxergar as tecnologias digitais como estando distantes da etapa escolar em que ele atua, e a importância de utilizar TDIC se concretiza como uma preparação do aluno para a próxima etapa e não como algo que pode integrar a rotina escolar 
dele nesse momento. O P8 traz uma consideração favorável ao uso das TDIC da mesma forma como outros professores o fizeram: aborda a possibilidade vantajosa de apresentar outras realidades ao aluno. Por fim, P9, diferentemente de P3 (Quadro 1) da Escola A, entende que o uso de tecnologias digitais maximiza seu tempo em sala de aula, já que o tempo dos alunos em contato com a língua é maior quando utilizam as TDIC.

É interessante destacar que 3 professores que haviam indicado importância média e 3 que haviam considerado extremamente importante o uso de tecnologias digitais na educação mantiveram suas respostas quando questionados sobre a importância das TDIC para as suas disciplinas. No entanto, todos os outros 5 professores atribuíram um grau de importância menor ao assunto quando se tratava das suas disciplinas.

Na categoria "Formação em TDIC voltadas à educação", 5 professores informaram não ter feito algum curso voltado ao uso de tecnologias digitais na educação. Dentre as razões para a não participação estão a falta de disponibilidade de tempo, o conflito de horários e o problema no transporte. Um dos professores afirma não lembrar de já ter recebido essa oportunidade através da mantenedora de maneira compensatória e destaca que buscou de forma autodidata o que julgou necessário e que já está prestes a se aposentar. Dentre os que disseram já ter realizado formação na área de TDIC, destacamos alguns depoimentos e os apresentamos no Quadro 3.

Quadro 3-Depoimentos de professores da Escola B

\begin{tabular}{|c|c|}
\hline Identificação & Depoimento \\
\hline $\begin{array}{l}\text { Professor do } 7^{\circ}, 8^{\circ} \text { e } 9^{\circ} \text { ano - } \\
\text { Lingua Portuguesa }(\mathrm{P} 10)\end{array}$ & $\begin{array}{l}\text { "Busquei algumas referências on-line, nada muito } \\
\text { complicado." }\end{array}$ \\
\hline $\begin{array}{l}\text { Professor dos anos iniciais }-1^{\circ} \text { ano } \\
\text { (P11) }\end{array}$ & $\begin{array}{l}\text { "Em } 2010 \text { realizei alguns cursos sobre o sistema } \\
\text { operacional Limux." }\end{array}$ \\
\hline $\begin{array}{l}\text { Professor do } 6^{\circ}, 7^{\circ}, 8^{\circ} \text { e } 9^{\circ} \text { ano - } \\
\text { Ciências (P7) }\end{array}$ & $\begin{array}{l}\text { "Realizei formações de algumas horas, oportunizada pela } \\
5^{\circ} \mathrm{CRE} \text { (NTE)." }\end{array}$ \\
\hline
\end{tabular}

Fonte: autores.

Pelo depoimento de P10, cabe questionarmos até que ponto sua busca online pode ser considerada uma formação em TDIC para a educação ou se foi uma simples pesquisa sobre algum tópico relacionado ao assunto. De forma similar, ainda que P11 tenha feito cursos sobre Linux, provavelmente o conhecimento por ele construído em 2010 não dê mais conta das suas necessidades enquanto professor em 2020, com todo o avanço que as tecnologias sofreram nesse intervalo de tempo. O depoimento de P7 nos mostra 
que, apesar de não ter sido um curso longo, o professor recebeu a oportunidade de participar de um curso proporcionado por um órgão público de educação e pôde aproveitá-la.

Na categoria "Percepção do uso das TDIC em suas aulas", 9 professores já haviam utilizado computador/notebook em suas aulas e, desses, 4 não haviam utilizado outras tecnologias digitais. Observamos que 5 professores já haviam utilizado smartphone na sala de aula, 3 haviam utilizado tablet e 3 haviam utilizado o computador interativo. Cabe destacar que só 1 professor informou já ter utilizado todas as TDIC apresentadas e 1 professor afirmou nunca ter feito uso de nenhuma delas, apesar de julgar extremamente importante o uso das tecnologias digitais tanto para a educação de modo geral quanto para a sua disciplina.

Ainda nessa categoria de análise, no que diz respeito à frequência de uso das TDIC podemos afirmar que os professores não lançam mão das tecnologias digitais frequentemente em suas aulas, como ficou evidenciado na Tabela 2.

Tabela 2 - Frequência de uso de tecnologias digitais em aula na Escola B

\begin{tabular}{|c|c|c|c|c|c|c|c|}
\hline \multirow{2}{*}{$\begin{array}{c}\text { Tecnologia } \\
\text { digital }\end{array}$} & \multicolumn{7}{|c|}{ Frequência de uso em aula } \\
\hline & Nunca & $\begin{array}{c}\text { 1x por } \\
\text { trimestre }\end{array}$ & $1 x$ por mês & $\begin{array}{c}1 \mathrm{x} \text { a cada } \\
15 \text { dias }\end{array}$ & $\begin{array}{l}\text { 1x por } \\
\text { semana }\end{array}$ & $\begin{array}{l}3 \mathrm{x} \text { por } \\
\text { semana }\end{array}$ & $\begin{array}{c}\text { Todas as } \\
\text { aulas }\end{array}$ \\
\hline $\begin{array}{l}\text { Computador/ } \\
\text { notebook }\end{array}$ & 3 & 3 & 1 & 3 & 1 & 0 & 0 \\
\hline Smartphone & 5 & 2 & 4 & 0 & 0 & 0 & 0 \\
\hline $\begin{array}{l}\text { Computador } \\
\text { interativo } \\
\text { (distribuido pelo } \\
\text { governo) }\end{array}$ & 8 & 0 & 0 & 3 & 0 & 0 & 0 \\
\hline Tablet & 10 & 0 & 1 & 0 & 0 & 0 & 0 \\
\hline
\end{tabular}

Fonte: autores.

A frequência de uso das tecnologias digitais nas aulas da Escola B é consideravelmente baixa, visto que a maioria das respostas se concentra nas duas primeiras colunas da tabela, indicando que a maior parte dos professores utiliza TDIC no máximo uma vez por trimestre em suas aulas. Por outro lado, 7 professores afirmaram já ter elaborado alguma atividade digital, o que indica um perfil autoral de grande parte desses profissionais.

Na percepção de vários professores, para que utilizassem as tecnologias digitais com maior frequência em suas aulas seria necessário que diversos aspectos da infraestrutura fossem melhorados: acesso à internet de qualidade e fornecimento de internet nas salas de aula, mais aparelhos na escola e 
mais computadores em funcionamento para uso dos alunos. A importância de ter mais tempo em sala de aula e de maior carga horária para os professores da sala de informática também foi apontada por 2 professores, além da necessidade de formação, conhecimento ou domínio, que foi percebida por 4 docentes. Por fim, um professor indicou total satisfação com o que a escola oferece, mas outros dois apontaram, individualmente, a necessidade de mais convencimento sobre a importância das TDIC e o acesso e domínio das tecnologias digitais por todos os alunos para que possam ter o mesmo aproveitamento.

Gráfico 2 - Ferramentas tecnológicas utilizadas em aula na Escola B

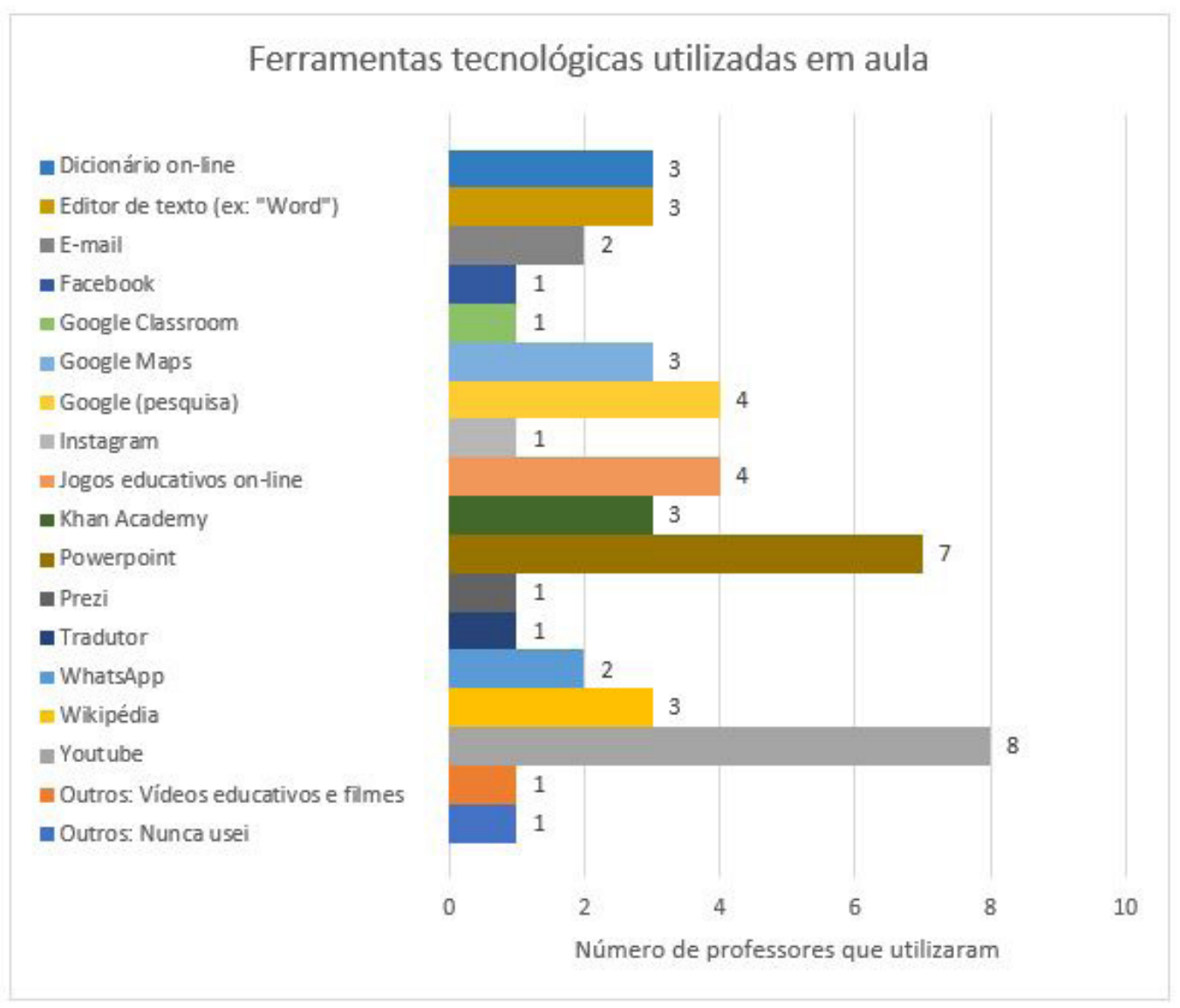

Fonte: autores.

Observamos que as quatro ferramentas tecnológicas adotadas por mais professores foram, respectivamente, as de gravação/exibição de vídeos, apresentação de conteúdo, pesquisa e jogos educativos. O segundo grupo de ferramentas mais utilizadas pelos professores contém aquelas relativas à edição de texto e leitura e obtenção de informações, bem como ferramentas de uso mais específico para determinadas disciplinas, como o dicionário 
online, o Google Maps e a Khan Academy. As redes sociais figuram entre as ferramentas menos utilizadas em sala de aula, acompanhadas pelo e-mail, Prezi e tradutor. Por não terem sido utilizadas por nenhum professor, foram suprimidas do Gráfico 2 as seguintes ferramentas tecnológicas: ELO - Ensino de Línguas Online, Kahoot, Nearpod, Skype e Twitter.

Na última categoria de análise, "Percepção de domínio de ferramentas digitais", os professores têm, em média, um bom domínio do computador/ notebook, um domínio regular do smartphone e do tablet e pouco domínio do computador interativo. Além disso, observamos uma tendência de os professores utilizarem mais frequentemente as tecnologias digitais que eles percebem dominar mais.

\subsection{Discussão}

Através da análise dos dados obtidos nos dois estudos de caso, percebemos que a realidade do uso de tecnologias digitais no segundo estudo de caso replica aquela observada no primeiro, apesar de percebermos alguns pontos de contraste nos dados analisados. Na categoria "Percepção da importância das TDIC na educação", confirmando o que se encontrou na Escola A, os professores da Escola B também consideram importante utilizar TDIC em sala de aula, mas ficou nítido que na Escola $B$ os professores não reconhecem tanta importância quando se trata do uso de TDIC nas suas disciplinas.

Na categoria "Percepção do uso das TDIC em suas aulas", a baixa frequência de uso das TDIC em sala de aula percebida no Caso 1 se confirma no Caso 2, mas com uma frequência ainda menor observada no segundo caso. Além disso, nas duas escolas pudemos perceber uma tendência de os professores utilizarem com mais frequência as tecnologias digitais que eles alegam ter maior domínio. Ainda nessa categoria, para que as tecnologias digitais fossem utilizadas com mais frequência os professores da Escola $A$ apontaram demandas similares às da Escola B: formação/domínio, tempo e acesso à internet, mas apenas os professores da Escola B abordaram a necessidade de mais computadores em funcionamento, apesar de ambas terem cerca de 20 notebooks em boas condições para uso dos alunos.

Constatamos que além de utilizar as TDIC com menos frequência, os professores da Escola B também fazem uso de menos ferramentas digitais e menos variedades de tecnologias digitais do que os professores da Escola A. Quanto a esse último aspecto, fazendo um cruzamento de dados verifi- 
camos em ambas as escolas que outros fatores (como idade, turmas atendidas, atribuição de importância ao uso de TDIC, zona em que residiu por mais tempo - urbana/rural) não implicaram necessariamente uma quantidade maior ou menor de tecnologias digitais utilizadas pelos professores. Quanto às ferramentas digitais, em ambas as escolas as redes sociais figuraram entre as ferramentas menos utilizadas em sala de aula, possivelmente por serem ferramentas que até pouco tempo não integravam o cenário escolar e, portanto, talvez não tenham seu potencial pedagógico reconhecido pelos docentes.

Na categoria "Formação em TDIC voltadas à educação", a realidade percebida no Caso 2 é diferente da que se observou no Caso 1, já que, enquanto 33\% dos docentes da Escola A havia participado de formação nessa área, na Escola B essa foi a realidade de $55 \%$ dos professores. É pertinente destacar que em ambas as escolas os professores que tiveram formação na área de TDIC voltadas à educação não só utilizam mais variedades de tecnologias digitais como também as utilizam com maior frequência do que aqueles que não participaram de formações na área. No entanto, contrariando o que naturalmente se esperaria da relação "Formação em TDIC" e "uso das TDIC" no contexto escolar, os professores da Escola B, embora superem os da Escola $A$ em participação de formações na área em questão, apresentam uma menor incorporação das tecnologias digitais às suas práticas pedagógicas. Presumimos que essa baixa adesão às TDIC mais fortemente evidenciada na Escola B seja reflexo da menor percepção de importância dos professores dessa escola sobre o uso de tecnologias digitais nas suas próprias disciplinas do que na educação de forma geral.

Finalmente, na categoria "Percepção de domínio de ferramentas digitais", constatamos que as ferramentas que os professores de ambas as escolas alegam usar com maior propriedade são, respectivamente: 1) computador/notebook; 2) smartphone; 3) tablet; 4) computador interativo; mas na Escola A os professores alegam ter o mesmo domínio do computador/ notebook e do smartphone. É curioso destacar que os graus de domínio das ferramentas digitais dos professores da Escola B são todos maiores do que os graus indicados pela Escola $A$, ainda que sejam valores próximos e não discrepantes. Portanto, pode-se concluir que, apesar de os docentes da Escola $B$ alegarem ter um maior domínio de TDIC do que os da Escola A, ainda assim eles são menos adeptos ao uso de tecnologias digitais nas suas aulas, provavelmente em consequência do menor reconhecimento de importân- 
cia que esses docentes atribuíram ao uso de TDIC nas suas disciplinas.

\section{QUAL É A REALIDADE DAS TDIC NAS ESCOLAS RURAIS EM 2020?}

Nesta pesquisa foram feitos dois estudos de caso para investigar a realidade das tecnologias digitais em duas escolas rurais de Pelotas-RS. Através de um questionário online, 20 professores, sendo 9 da Escola A e 11 da Escola $B$, expuseram suas perspectivas e relataram suas experiências acerca do uso das TDIC em sala de aula.

Através dos dados obtidos percebemos que as tecnologias digitais já são uma realidade nas escolas rurais, visto que dos 20 participantes da pesquisa, apenas 1 relatou nunca ter utilizado uma tecnologia digital em sala de aula. Por outro lado, se voltarmos o olhar para a frequência de uso dessas TDIC, vemos que essa realidade está longe de ser o que se esperaria encontrar no cenário educacional em 2020.

Acreditamos que seja difícil e simplista apontar um único motivo pelo qual as tecnologias digitais ainda não fazem parte da rotina escolar de professores e alunos, mas, com base nas análises feitas, consideramos que alguns elementos podem ter grande influência na realidade observada. Sabendo que os professores utilizam mais frequentemente as tecnologias digitais que eles dominam mais e que há uma tendência de os professores que participaram de formação sobre TDIC na educação fazerem maior uso dessas ferramentas em suas práticas, podemos presumir que talvez os professores não se sintam seguros e confiantes o suficiente para inserir as TDIC em suas aulas de forma mais habitual, o que nos leva a refletir sobre a indispensabilidade de cursos de formação de qualidade para capacitar esses profissionais na implementação das tecnologias digitais em sala de aula. Outro aspecto importante, e que foi amplamente apontado pelos participantes, é a necessidade de melhorias na infraestrutura das escolas, tais como melhor conexão com a internet, já que os próprios professores afirmaram que essa melhoria culminaria em uma maior utilização das tecnologias digitais nas suas práticas pedagógicas.

Por fim, gostaríamos de retomar a ideia já discutida anteriormente de que os professores que estão nas salas de aula hoje ainda são frutos de uma educação que teve pouquíssima, se alguma, intervenção de tecnologias digitais. Logo, a utilização dessas ferramentas não costuma fazer parte do seu imaginário sobre o que é dar aula. Muito provavelmente vários deles discutiram sobre e foram muito encorajados na faculdade a fazer uso das 
tecnologias digitais quando fossem dar aulas, mas, como disse Paiva (2012), as mudanças acontecem aos poucos e são muitos os elementos que interferem no contexto educacional.

Apesar de essa realidade não representar o cenário ideal da atuação das TDIC nas salas de aula das escolas rurais, vemos com otimismo o caminho que tem sido trilhado pelos profissionais da educação. Percebemos um reconhecimento significativo da importância do uso de tecnologias digitais na educação por parte dos professores, o que, para nós, é um passo determinante rumo a uma incorporação dessas ferramentas ao ambiente escolar. Além disso, como as escolas do campo são sempre lembradas como as outras (ARROYO, 2007), podemos presumir que a realidade das tecnologias digitais nas escolas urbanas esteja um pouco menos distante do cenário ideal, já que estas tendem a receber mais investimentos do que as escolas de zona rural. Por fim, a necessidade de isolamento social gerada pela pandemia da COVID-19 trouxe consigo a necessidade de adaptação às tecnologias digitais em inúmeras áreas, inclusive, e principalmente, na educação. É possível que, com a imprescindibilidade da inserção das TDIC na rotina da educação remota durante a referida pandemia, essas ferramentas passem a fazer parte das aulas no imaginário do corpo docente e, consequentemente, integrem o ensino presencial no mundo pós-pandemia.

\section{REFERÊNCIAS}

ARROYO, Miguel Gonzalez. Políticas de Formação de Educadores(as) do Campo. Cadernos Cedes, Campinas, vol. 27, n. 72, p. 157-176, maio/ago. 2007. Disponível em: <http:// www.scielo.br/pdf/ccedes/v27n72/a04v2772.pdf>. Acesso em: 23 abr. 2020.

BOHN, Hilário. Maneiras inovadoras de ensinar e aprender: A necessidade de des(re)construção de conceitos. In: LEFFA, V. (Org.). O Professor de Línguas: Construindo a profissão. Pelotas: Educat, 2001. Disponível em: <http://www.leffa.pro.br/tela4/Textos/Textos/ Livros/Professor_de_linguas.pdf $>$. Acesso em: 23 abr. 2020.

BRASIL. Ministério da Educação. Base Nacional Comum Curricular. Brasília: MEC/SEB, 2018. Disponível em: <http://basenacionalcomum.mec.gov.br/>. Acesso em: 16 mai. 2020.

DINIZ, Sirley. $O$ uso das novas tecnologias em sala de aula. 2001. 173 p. Dissertação (Mestrado em Engenharia de Produção) - Programa de Pós-graduação em Engenharia de Produção, Universidade Federal de Santa Catarina, Centro Tecnológico. Santa Catarina, 173p. 2001. Disponível em: <http://repositorio.ufsc.br/xmlui/handle/123456789/81758 >. Acesso em: 23 abr. 2020.

ENGESTRÖM, Y. Activity theory and individual and social transformation. In: ENGESTRÖM, Y.; MIETTINEN, R.; PUBAMAKI, R. L. (Eds). Perspectives on Activity Theory. Cambridge: Cambridge University Press, 1999. 
JOHNSON, Steven. Como chegamos até aqui: a história das inovações que fizeram a vida moderna possível. 1 ed. Rio de Janeiro: Zahar, 2015. Disponível em: <https://zahar.com. $\mathrm{br} / \mathrm{sites} /$ default/files/arquivos/trecho_ComoChegamosAteAqu.pdf>. Acesso em: 23 abr. 2020.

LARSEN-FREEMAN, Diane. Chaos/complexity science and second language acquisition. Applied Linguistics, v. 18, issue 2, June 1997, pp. 141-165.

LEFFA, Vilson José. Vygotsky e o ciborgue. In: SCHETTINI, Rosemary H.; DAMIANOVIC, Maria Cristina; HAWI, Mona M.; SZUNDY, Paula Tatianne C. (Orgs.). Vygotsky: uma revisita no início do século XXI. São Paulo: Andross Editora, 2009. Versão online. Disponível em: <http://www.leffa.pro.br/textos/trabalhos/Vygotsky_hp_portugues.pdf>. Acesso em: 23 abr. 2020.

LEVY, Neil. Cyborgs-R-Us. ACM International Conference Proceeding Series, v. 101. Selected papers from conference on Computers and Philosophy, v. 37, 2003. Disponível em: <https://dl.acm.org/doi/pdf/10.5555/1082145.1082148>. Acesso em: 23 abr. 2020.

MADEIRO, Carlos. Escola da zona rural de Alagoas supera pobreza e tem maior Ideb do país. UOL. Coruripe. 06 set 2018. Disponível em: <https://educacao.uol.com.br/noticias/2018/09/06/escola-da-zona-rural-de-alagoas-supera-pobreza-e-tem-maior-ideb-do-pais.htm>. Acesso em: 23 abr. 2020.

MORIN, Edgar. Introdução ao pensamento complexo. 2. ed. Lisboa: Instituto Piaget, 1995. $177 \mathrm{p}$.

PAIVA, V.L.M.O. Modelo fractal de aquisição de línguas. In: BRUNO, F.C. (Org.) Reflexão e Prática em ensino/aprendizagem de língua estrangeira. São Paulo: Editora Clara Luz, 2005. p. 23-36. Disponível em: <http://www.veramenezes.com/modelo.htm>. Acesso em: 31 jul. 2020.

- Inovações tecnológicas: o livro e o computador. In: VETROMILLE-CASTRO, R.; HEEMANN, C.; FIALHO, V. (Orgs.). Aprendizagem de Línguas - a Presença na Ausência: CALL, Atividade e Complexidade. Pelotas: EDUCAT, 2012. p. 13-29.

TRIBUNA DO NORTE. Especialistas alertam sobre uso de celular na escola: vilão ou aliado?. Natal, 2020. Disponível em: <http://www.tribunadonorte.com.br/noticia/especialistas-alertam-sobre-uso-de-celular-na-escola-vila-o-ou-aliado/473371>. Acesso em: 23 abr. 2020.

VYGOTSKY, Lev. The instrumental method in psychology. In: RIEBER, R.; WOLLOCK (Eds.), The Collected Works of L. S. Vygotsky: Vol. 3 Problems of the Theory and History of Psychology. Nova York: Plenum, 1997, p. 85-89.

VYGOTSKY, Lev; LURIA, Alexander; LEONTIEV, Alex. Linguagem, desenvolvimento e aprendizagem. 11 ed. São Paulo: ícone, 2010.

YIN, Robert. Estudo de caso: planejamento e métodos. 2 ed. Porto Alegre: Bookman, 2001. 


\section{Nairana Hoffmann Sedrez}

Possui Mestrado em Linguística Aplicada pela Universidade Católica de Pelotas (UCPel) e atualmente é doutoranda do Programa de Pós-Graduação em Letras da Universidade Federal de Pelotas (UFPel) e professora da rede municipal de Pelotas.

E-mail: nairana_sedrez@hotmail.com

\section{Rafael Vetromille Castro}

Doutor em Informática na Educação pela UFRGS, atualmente é professor do PPG em Letras e professor associado na área de língua inglesa do Centro de Letras e Comunicação da UFPel. Desenvolveu pós-doutorado na University of California/Berkeley na área de Linguística Aplicada.

E-mail: rafael.vetromille@ufpel.edu.br 